\title{
PENGARUH KUALITAS PELAYANAN, KUALITAS PRODUK DAN HARGA TERHADAP LOYALITAS PELANGGAN (STUDI KASUS LADYFAME BANDAR LAMPUNG)
}

\author{
Nunung Yuliawati ${ }^{(1)}$, Artia Rahmawati ${ }^{(2)}$, Ella $^{(3)}$,Vicky F Sanjaya ${ }^{(4)}$ \\ Universitas UIN Raden Intan Lampung \\ email:nunungyulia04@gmail.com,Vicky@ radenintan.ac.id
}

\begin{abstract}
Abstrak. Penelitian ini bertujuan untuk mengetahui pengaruh kualitas pelayanan,kualitas produk dan harga terhadap loyalitas pelanggan Toko Ladyfame di Bandar Lampung. Jenis penelitian kuantitatif Sebanyak 71 pelanggan diambil sebagai sampel melalui metode purposive sampling. Teknik pengumpulan data menggunakan kuesioner. Perolehan hasil penelitian didapatkan bahwa kualitas pelayanan lebih berpengaruh signifikan daripada kualitas produk dan harga terhadap loyalitas pelanggan Ladyfame. Berdasarkan penelitian yang dilakukan bahwasannya kualitas pelayanan, kualitas produk dan harga berpengaruh terhadap loyalitas pelanggan Toko Ladyfame $\mathrm{d} i$ Bandar Lampung
\end{abstract}

Kata Kunci : Pelayanan,Produk,harga, Loyalitas pelanggan.

\begin{abstract}
This study aims to determine the effect of service quality, product quality and price on customer loyalty at the Ladyfame Store in Bandar Lampung. This type of research quantity 71 customers taken as a sample through purposive sampling method. Data collection techniques using a questionnaire. The results of the study showed that service quality had a more significant effect than product quality and price on Ladyfame's customer loyalty. Based on the research conducted, the quality of service, product quality and price affect customer loyalty at the Ladyfame Store in Bandar Lampung
\end{abstract}

Keywords: Service, product, price, customer loyalty.

\section{PENDAHULUAN}

Semakin banyaknya jumlah orang yang ingin tampil kekinian dan sesuai denga mode masa kini membuat konsumen juga membutuhkan tempat untuk membeli kebutuhan yang sesuai dengan mode masa kini yang di butuhkannya. Hal ini menimbulkan persaingan yang ketat antara para pengusaha di bidang pakaian dalam meningkatkan produk-produk yang di produksinya utuk menarik perhatian para konsumen. oleh karna itu para pengusaha berusaha untuk lebih meningkatkan dan mencari alternatif bagaimana caranya membuat para konsumen merasa puas atas apa yang di berikan pengusaha agar konsumen menjadi loyal.

Akan tetapi untuk menumbuhkan loyalitas pelanggan bukanlah hal yang mudah untuk dibentuk, karena para pengusaha harus lah terlebih dahulu memberikan apa yang di inginkan pelanggannya agar dia merasa puas. Loyalitas pelanggan biasanya terbentuk karna dia mendapat tingkat pelayanan yang baik yang memberikan rasa puas pelanggan juga memastikan untuk mendapatkan kualitas produk yang bagus dengan harga yang relatif murah. Ladyfame Bandar Lampung merupakan salah satu toko yang bergerak di bidang usaha pakaian wanita. Yang didalamnya 
terdapat banyak barang prduksi yang dibuat sendiri maupun mengambil barang dari produksi lain atau bisa di katakan menjadi reseller.

Dalam perkembangannya, jumlah pelanggan Ladyfame Bandar Lampung mengalami peningkatan yang sangat pesat beberapa tahun terakhir ini tetapi tidak luput pula dengan naik turunnya jumlah pelanggan karna diakibatkan ketatnya persaingan dengan kemunculan toko-toko baru. Adanya naik-turun dalam hal tingkat kepuasaan pelanggan, sehingga pelanggan mengalami penurunan karna tergiur dengan toko-toko baru. Yang membuat Ladyfame Bandar Lampung harus mengevaluasi kembali hal-hal yang menjadi turunnya tingkat kepuasaan pelanggan, Hal- hal yang di evaluasi oleh Pihak Ladyfame Bandar lampung yaitu Kualitas terhadap pelayanan dan produk serta harga yang menjadi hal-hal yang di evaluasi guna meningkatkan Loyalitas Pelanggan Ladyfame Bandar Lampung.

Kualitas Pelayanan yang baik yang diberikan oleh pengusaha akan memberikan rasa nyaman kepada konsumen dan meningkatkan keloyalan pada konsumen. Karna menurut (Minh 2016) menjelaskan tentang apa saja yang perlu diperhatikan didalam kualitas pelayanan demi mendatangkan pelanggan loyal yaitu dengan kualitas pelayanan yang baik dengan keandalan atau kemampuan perusahaan untuk melaksanakan jasa sesuai dengan apa yang telah dijanjikan secara tepat waktu yang menjadikan tolak ukur dan yang terjadi adalah terciptanya loyalitas pelanggan.Sedangkan menurut Hadiyati karna mnurut (Zeithaml dan Bitner 2003:81) yang menjelaskan bahwa kepuasaan pelanggan dipengaruhi oleh kualitas produk,kualitas pelayanan atau jasa,emosi harga dan biaya. Dan juga menurut (Yesenia and Siregar 2014) apabila pelanggan sudah merasa puas maka selanjutnya tinggal mempertahankan loyalitas pelanggan, kepuasaan pelanggan sangat bergantung penilaan pelanggan terhadap kualitas dari produk atau jasa yang di tawarkan.

Kualitas produk juga haruslah benar-benar baik dan sesuai dengan yang di inginkan konsumen agar menambah keloyalan konsumen hal ini dikatakan juga oleh ( Kotler dan Amstrong 2009) dikatakan kualitas produk adalah suatu karakteristik dan produk yang memiliki kemampuan untk memenuhi kebutuhan pelanggan sesuai dengan ketentuan tertentu dan bersifat latin. Dan menurut (Pardede,2015). berpendapat Meningkatkan kualitas produk merupakan cara perusahaan dalam meningkatkan loyalitas pelanggan. Hal ini dapat dilihat dengan melalui produk yang dinilai sudah terbukti baik dengan melihat riwayat dari produk tersebut yang tersebar di masyarakat yaitu kemampuan dan kesanggupan untuk membantu konsumen dan menyediakan produk sesuai ketentuan , walaupun mereka berganti label produk tetapi konsumen tetap memilih produk tersebut karena memiliki hubungan yang kuat dengan produk tersebut.

mayoritas orang ketika belanja yang dilihat di awal adalah harganya baru kualitas produk kualitas pelayanan, sebagian orang atau bahkan mayoritas lebih suka dengan produk yang harganya lebih murah hal ini di perkuat juga oleh pendapat ( Handayani 2015) mengemukakan dalam penelitianya bahwa semakin rendah/murah persepsi harga yang diberikan akan semakin meningkatkan loyalitas pelanggan, demikian pula sebaliknya semakin tinggi atau mahal persepsi harga yang diberikan akan mengurangi loyalitas pelanggan. (Tomida 2016) mengemukakan untuk menjadikan loyalitas pelanggan perusahan harus memperhatikan kebijakankebijakan harga yang selalu akan di 
terapkan untuk memperhatikan dampak pada loyalitas pelanggan itu sendiri. Sedangkan (Pongoh 2013) didalam penelitianya adanya pesaing yang kuat membuat persepsi harga yang dilihat konsumen untuk loyal akan berkurang dan akan berpindah mencari yang lebih murah. Loyalitas pelanggan adalah kesedian pelanggan untuk terus membeli dari suatu perusahaan dalam jangka panjang dan membuat rekomendasi atas produk atau merek yang dai sukai kepada teman dan rekan, termasuk preferensi, keinginan dan niat masa depan (Lovelock 2011) sedangkan Menurut (Tjiptono 2014) loyalitas konsumen adalah komitmen pelanggan terhadap suatu merek, toko atau pemasok berdasarkan sifatyang sangat positif dalam pembelian jangka panjang. Artinya, bahwa kesetiaan terhadap merek diperoleh karena adanya kombinasi dari kepuasan dan keluhan.Berdasarkan uraian di atas maka penulis tertarik untuk meneliti dan menjadikannya bahan penelitian dengan jurul "Pengaruh Kualitas Pelayana, Kualitas Produk Dan Harga Terhadap Loyalitas Pelanggan" dengan studi kasus pelanggan Ladyfame Bandar Lampung.

\section{METODE PENELITIAN}

\section{a. Populasi dan Sample}

Populasi pada penelitian ini adalah Orang yang pernah membeli barang atau menjadi pembeli produk Ladyfame Bandar Lampung. Jumlah sample yang di gunakan pada penelitian ini berjumlah 71 responden, dengan teknik pengambilan sample menggunakan Purposive sampling. Dengan menggunakan Metode Kuantitatif.

\section{b. Metode Pengumpulan Data}

Menggunakan Metode Kuantitatif yaitu dengan menyebarkan Kuesioner metode pengukuran data kuantitatif dan statistika objektif melalui perhitungan ilmiah berasal dari sampel Pelanggan Ladyfame yang diminta menjawab sejumlah pertanyaan tentang survei untuk menentukan frekuensi dan persentase tanggapan mereka. Tujuan penelitian ini akan menentukan dalam memilih metode penelitian yang akan digunakan.

\section{c. Jenis dan Sumber data}

Sumber data terbagi menjadi dua yaitu data primer dan data sekunder.

a. Data primer adalah data yang diperoleh peneliti secara langsung (dari tangan pertama), sementara data sekunder adalah data yang diperoleh peneliti dari sumber yang sudah ada. Contoh data primer adalah data yang diperoleh dari responden melalui kuesioner, kelompok fokus, dan panel, atau juga data hasil wawancara peneliti dengan nara sumber.

b. data sekunder merupakan berbagai informasi yang telah ada sebelumnya dan dengan sengaja dikumpulkan oleh peneliti yang digunakan untuk melengkapi kebutuhan data penelitian.Contoh data sekunder misalnya catatan atau dokumentasi perusahaan berupa absensi, gaji, laporan keuangan publikasi perusahaan, laporan pemerintah, data yang diperoleh dari majalah, dan lain sebagainya.

\section{HASIL DAN PEMBAHASAN}

Sebelum uji T- statistik, terlebih dahulu di lakukan uji Validitas dan Reabilitas terhadap data yang akan di teliti. Untuk menghindari data-data yang tidak valid yang dapat mengakibatkan terjadinya ketidak optimalan dalam penelitian Dari hasil Validitas dan Reabilitas yang kami Lakukan terdapat beberapa indikator yang tidak memenuhi Standar sehingga perlu di hapus . Pada Variabel X1 (Kualitas Pelayanan) terdapat 2 pertanyaan yang tidak memenuhi standar dari 7 pertanyaan sedangkan pada X2 (Kualitas Produk) terdapat 3 yang tidak memenuhi standar 
dari 7 pertanyaan sedangkan pada X3 (Harga) keempatnya memnuhi Standar dan pada Y (Loyalitas Pelanggan ) hanya satu yang tidak memenuhi Standar dari 6 pertanyaan.

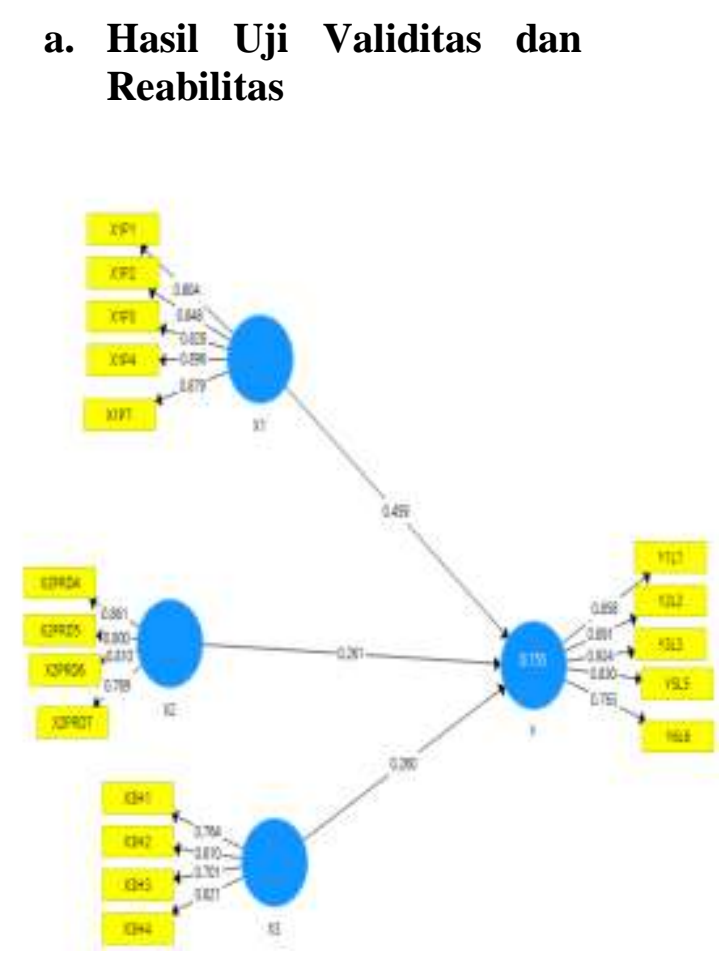

a. Hasil Uji Hipotesis

\begin{tabular}{|c|c|c|c|c|c|}
\hline & $\begin{array}{l}\text { Origi } \\
\text { nal } \\
\text { samp } \\
\text { le } \\
\text { (O) }\end{array}$ & $\begin{array}{l}\text { Sam } \\
\text { ple } \\
\text { mea } \\
\text { n } \\
(\mathrm{M})\end{array}$ & $\begin{array}{c}\text { Stand } \\
\text { ard } \\
\text { Devia } \\
\text { tion } \\
\text { (STD } \\
\text { EV) }\end{array}$ & $\begin{array}{c}\mathrm{T} \\
\text { Statistic } \\
(\mathrm{IO} / \mathrm{STD} \\
\text { EVI) }\end{array}$ & $\begin{array}{l}\mathrm{P} \\
\text { Va } \\
\text { lue } \\
\mathrm{s}\end{array}$ \\
\hline $\begin{array}{l}\text { Kualit } \\
\text { as } \\
\text { Pelaya } \\
\text { nan -> } \\
\text { Loyali } \\
\text { tas } \\
\text { Pelan } \\
\text { ggan }\end{array}$ & $\begin{array}{r}0.24 \\
8\end{array}$ & $\begin{array}{r}0.25 \\
0\end{array}$ & 0.109 & 2.264 & $\begin{array}{r}0 . \\
02 \\
4\end{array}$ \\
\hline $\begin{array}{l}\text { Kualit } \\
\text { as } \\
\text { Produ } \\
\mathrm{k}-> \\
\text { Loyali } \\
\text { tas }\end{array}$ & $\begin{array}{r}0.46 \\
4\end{array}$ & $\begin{array}{r}0 \\
.464\end{array}$ & 0.075 & 6.169 & $\begin{array}{r}0 . \\
00 \\
0\end{array}$ \\
\hline
\end{tabular}

\begin{tabular}{lrrrrr}
\hline $\begin{array}{l}\text { Pelan } \\
\text { ggan }\end{array}$ & & & & & \\
& & & & \\
& & & & & \\
Kualit & 0.26 & 0.26 & 0.114 & 2.356 & 0. \\
as & 7 & 6 & & & 01 \\
Produ & & & & & 9 \\
k -> & & & & & \\
Loyali & & & & & \\
tas & & & & & \\
Pelaya & & & & \\
nan & & & & \\
\end{tabular}

Berdasarkan hasil analisis, dapat disimpulkan bahwa hasil dari pengujian hipotesis dalam penelitian iniadalah sebagai berikut :

H1 : Kualitas pelayanan berpengaruh positif signifikan terhadap loyalitas pelanggan

Pada tabel ini menguji apakah kualitas pelayanan berpengaruh secara positif terhadap loyalitas pelanggan. Hasil pengujian menunjukkan bahwa nilai koefisien beta kualitas pelayanan terhadap loyalitas pelanggan sebesar 0.248 dan $\mathrm{t}$ statistik 2.264. dari hasil dinyatakan tstatistik signifikan karena $>1,96$ dengan $\mathrm{p}$ value $<0,05$ yaiu 0.024 sehingga hipotesis pertama diterima. Hal tersebut membuktikan bahwa kualitas pelayanan berpengaruh positif signifikan terhadap loyalitas pelanggan

H2 : Kualitas Produk berpengaruh positif signifikan terhadap loyalitas pelanggan

Pada tabel ini menguji apakah kualitas Prosuk berpengaruh secara positif terhadap loyalitas pelanggan. Hasil pengujian menunjukkan nilai koefisien beta Kualitas Produk terhadap loyalitas 
pelanggan sebesar 0.464 dan t-statistik sebesar 6.169. dari hasil dinyatakan tstatistik signifikan karena $>1,96$ dengan $\mathrm{p}$ value $<0,05$ yaiu 0.000 sehingga hipotesis kedua diterima. Hal tersebut membuktikan bahwa kualitas produk berpengaruh positif signifikan terhadap loyalitas pelanggan

H3: Harga berpengaruh positif signifikan terhadap loyalitas pelanggan

Pada tabel ini menguji apakah harga berpengaruh secara positif terhadap loyalitas pelanggan. Hasil pengujian menunjukkan nilai koefisien beta harga terhadap loyalitas pelanggan sebesar 0.267dan t-statistik yaitu sebesar 2.356. dari hasil ini dinyatakan $\mathrm{t}$-statistik signifikan karena $>1,96$ dengan $\mathrm{p}$-value $<0,05$ yaitu 0.019 sehingga hipotesis ketiga diterima. Hal tersebut membuktikan bahwa harga berpengaruh positif signifikan terhadap loyalitas pelanggan .

\section{KESIMPULAN}

Berdasarkan hasil penelitian yang dilakukan bahwa :

1. Kualitas berpengaruh positif dan signifikan terhadap Loyalitas Pelanggan Ladyfame Bandar Lampung.karna T-statistik $2.264>2.000$ dan P-value $0.024<0.500$.

2. Kualitas Produk berpengaruh Positif dan signifikan terhadap Loyalitas Pelanggan Ladyfame Bandar Lampung karna T-Statistik $6.169>$
2.000 dan P-Value $0.000<$ 0.500 .

3. Harga berpengaruh positif dan signifikan terhadap Loyalitas Pelanggan Ladyfame Bandar Lampung karna T-Statistik $2.356>$ 2.000 dan P-Value 0.024< 0.500 .

\section{SARAN}

Disarankan kepada Ladyfame Bandar Lampung untuk dapat lebih memberikan kualitas Pelayanan, Kualitas Produk dan Harga yang terbaik karna ketiga hal ini memberikan pengaruh yang positif dan signifikan terhadap keloyalan Pelanggan Ladyfame Bandar Lampung. Agar dapat bertahan di bawah persaingan- persaingan yang semakin meningkat. Untuk peneliti selanjutnya di sarankan agar menambah Variabel-variabel lain yang berhubungan dengan loyalitas pelanggan serta Studi kasus yang berbeda agar mendapat hasil yang lebih bervarasi.

\section{DAFTAR PUSTAKA}

Bitner, M. J. dan Zeithaml, V. A., 2003, Service Marketing (3rd ed.), Tata McGraw Hill, New Delhi.

Handayani, W. 2015. Pengaruh Citra dan Persepsi Harga Dalam Mempengaruhi Kepuasan dan Dampaknya Terhadap Loyalitas Pelanggan. Jurnal Ekonomi. 1-27

Kotler dan Keller. 2009. Manajemen Pemasaran. Jilid Satu, Edisi Kedua Belas. Alih Bahasa Benyamin. Jakarta: PT. Indeks. Kelompok Gramedia.

Lovelock, Wirtz dan Mussry. (2011). Pemasaran Jasa: Manusia, 
Teknologi, Strategi. Jakarta: Erlangga.

Minh ,Ngo Fu., Nguyen Huan H. (2016). The Relationship between Service Quality, CustomerSatisfaction and Customer Loyalty: An Investigation in Vietnamese Retail Banking Sector. Journal of Competitiveness.

Pardede, F. P. 2015. Pengaruh Kualitas Produk, Merek Dan Promosi Terhadap LoyalitasPelanggan Rokok. Jurnal Manajerial. Vol. 9. No. 1.

Pongoh, M. E. 2013. Kualitas Pelayanan, Kualitas Produk, dan Harga Pengaruhnya Terhadap Loyalitas Pelanggan Kartu AS . Jurnal EMBA Vol.1. No.4

Tjiptono ,Fandy, 2014. Pemasaran Jasa: Prinsip,Penerapan,Penelitian, Edisi ke-3 Yogyakarta : Andi

Tomida, Merinda. 2016. Pengaruh Harga dan Citra Merk terhadap Loyalitas Pelanggan Produk Footwear Yongki Komala.

Yesenia, and Edward H Siregar. 2014. "Pengaruh Kualitas Layanan Dan Produk Terhadap Kepuasan Serta Loyalitas Pelanggan Kentucky Fried Chicken Di Tangerang Selatan." Jurnal Manajemen Dan Organisasi Vol V, No 3, Desember 2014. 